\title{
LATERAL BEHAVIOUR OF STEEL FRAMES WITH PRECAST REINFORCED CONCRETE EXTERIOR INFILL PANELS
}

\author{
ASHRAF OSMAN \& MOHAMED G. KHERD \\ Structural Engineering Department, Cairo University, Egypt
}

\begin{abstract}
This study investigates the lateral behaviour of steel moment resisting frames cladded externally with precast reinforced concrete panels, under the action of both wind and earthquake loads. The aim is to explore the possibility of achieving extra saving in the steel structure weight by utilizing the external cladding to engage in resisting the applied lateral loads. To achieve these objectives, several hypothetical steel moment-resisting frames were initially developed. Then, these frames were analysed using a push-over technique. In performing these analyses and for sake of comparison, the frames were considered as bare steel frames once and in other cases the contribution of the external reinforced concrete cladding panels was included. The structural elements of the analysed moment resisting frames (beams and columns) were modelled analytically using a beam-column element that allow the formation of plastic hinges at elements ends, while the external reinforced concrete precast cladding panels were modelled using equivalent diagonal struts that can yield and possess a criterion for collapse that simulates the possibility of failure of connection between panels and steel frames. For all performed analyses, lateral stiffness, strength, and sequence of plastic hinging were evaluated and compared. It was concluded that utilizing precast concrete external panels' contribution in designing moment resisting frames against wind loads can improve significantly frames' initial stiffness and strength, leading to significant reduction in their steel tonnage. For designing against earthquake loads, the panels limited frames' lateral deformation and reduced their weights which was considered beneficial in resisting minor and moderate earthquakes and limiting the damage to non-structural elements. However, at ultimate state under severe earthquakes, to maximize the contribution of these panels, the connections between the steel frames and the panels needs to be sufficiently strong to ensure engagement of panels in resisting the lateral loads, and frames should be detailed for a strong columnweak beam concept.
\end{abstract}

Keywords: seismic behaviour, steel moment resisting frames, precast reinforced concrete panels, exterior cladding.

\section{INTRODUCTION}

In today's building practice, steel moment resisting frames with exterior precast reinforced concrete infill panels are commonly used in construction. However, engineers often ignore the existence of these panels in the design process because they are regarded as non-structural elements. This is attributed to lack of knowledge concerning the contribution of these panels to frames lateral stiffness and strength. Historically, many experimental and theoretical research studies tried to reach an adequate expression for the behaviour of structural frames integrating exterior cladding panels [1]-[3]. They utilized finite element models through analyses to evaluate the effects of considering the exterior panels in the analysis on frames lateral stiffness, roof displacement and sequence of plastic hinges formation. In general, it was noted that exterior panels tend to decrease frames lateral sway, increase initial lateral stiffness and in some cases increase frames strength, but how this can be beneficial to these frames?

In practice, separation between these panels and the frames is not usually provided which leads to the panels engaging in resisting the lateral loads acting on these frames. On the other 
hand, several design codes identify serviceability sway limits for frames under the action of wind and seismic loads. Therefore, in this study the lateral behaviour of hybrid structural system consisting of a steel moment resisting frame combined with exterior reinforced concrete precast infill panels is investigated. The main objectives of this study are to assess the contribution of these panels in resisting the applied lateral loads on frames, exploring the benefits that can be gained from utilizing them in the analysis, and providing design recommendations to maximize these benefits.

\section{HYPOTHETICAL STRUCTURE}

To achieve these objectives, a hypothetical residential building having $(12.0 \times 16.0 \mathrm{~m})$ in plane dimensions and story height of $4.0 \mathrm{~m}$ was configured as shown in Fig. 1. The structure is formed by intersection of three parallel two bay plan frames disposed along each of the two orthogonal directions of the building. Each building floor was assumed to support gravity loads consist of dead load equal to $665 \mathrm{~kg} / \mathrm{m}^{2}$ accounting for the weight of concrete slab, partition, and flooring and live load equal to $250 \mathrm{~kg} / \mathrm{m}^{2}$ in addition to its self-weight.

For resisting lateral loads (wind or earthquake loads) in east-west direction, only exterior moment resisting frames along axes $\mathrm{A}$ and $\mathrm{C}$ were considered, while frame $\mathrm{B}$ was assumed to be leaning frame. In north-south direction, the frames along axes 1 and 3 were braced and the frame along axis 2 was assumed to be leaning frame. The structure was cladded externally with precast panels that were connected at each level with steel anchorage connections at the steel building edge beams. These connections are vertically slotted at the top level of panels and hinged at the bottom level of panels. The study is concerned with investigating the behaviour of moment resisting frames along axes $\mathrm{A}$ and $\mathrm{C}$.

The intensity of wind lateral pressure acting on the frames was calculated in accordance with the Egyptian code of practice for loads [4] assuming that the wind speed is $36 \mathrm{~m} / \mathrm{s}$ in building location, while the seismic load was calculated in accordance with the Egyptian code

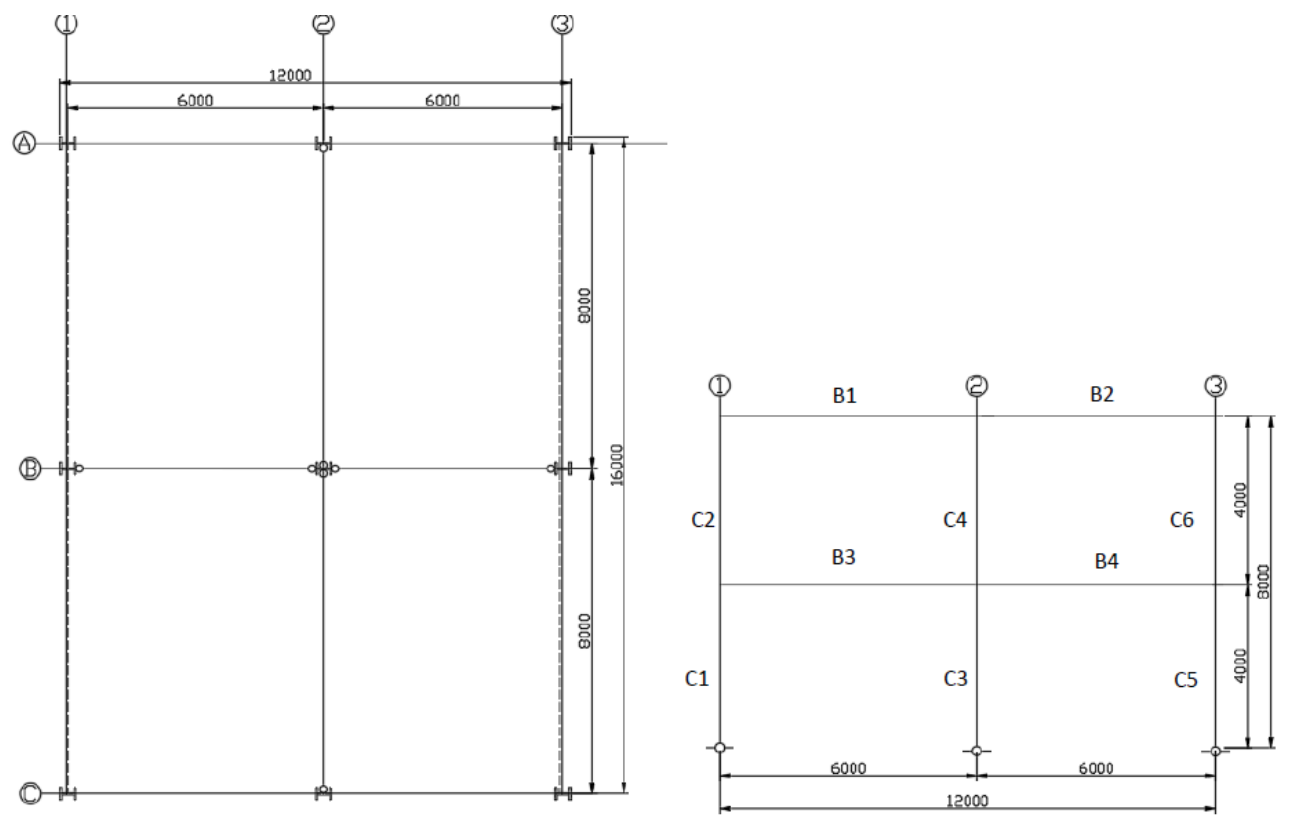

Figure 1: Plan and section elevation to the hypothetical building. 
of practice for loads assuming that the peak ground acceleration is equal to $0.2 \mathrm{~g}$, soil class is $\mathrm{A}$ and the moment resisting frames are of limited ductility (intermediate moment resisting frames) with reduction coefficient equal to 5 .

Four steel moment resisting frames were designed representing different scenarios. In the first scenario, the frame, designated in this study as model A, was designed to support gravity and wind loads only with no consideration to code drift limit which is equal to $\mathrm{H} / 500$, where $\mathrm{H}$ is the floor height. In other words, it is designed to satisfy only strength requirements neglecting drift requirements. In the second scenario, the frame, designated in this study as model B, was designed to support gravity and wind loads and satisfying the code drift limits. Consequently, it was designed to satisfy both strength and drift limitations. Table 1 shows beams and columns cross-sections for the two frames. As can be noted, the weight of frame $\mathrm{A}$ is $35 \%$ less than that of frame $\mathrm{B}$.

Table 1: Cross-sections of structural elements for frames A and B.

\begin{tabular}{|l|c|c|}
\hline Beam/Column sections & Frame A & Frame B \\
\hline Beams B1, B2, B3 and B4 & HEB240 & HEA300 \\
\hline Columns C1, C2, C5 and C6 & HEA220 & HEA400 \\
\hline Columns C3 and C4 & HEA260 & HEA400 \\
\hline Total tonnage per frame & 3.34 & 5.2 \\
\hline
\end{tabular}

In the third scenario, the frame, designated in this study as model $\mathrm{C}$, was designed to support gravity and earthquake loads only with no consideration to code drift limit which is equal to $\mathrm{H} / 50$ during inelastic action, where $\mathrm{H}$ is the floor height. In other words, it is designed to satisfy only strength requirements with no consideration to drift limits. In the fourth scenario, the frame, designated in this study as model D, was designed to support gravity and earthquake loads and satisfying the drift limits. Table 2 shows the cross-sections for the beams and columns for the two frames. As can be noted, the weight of frame $\mathrm{C}$ is $31 \%$ less than that of frame D.

For all frames, the beams and columns were high-grade steel S 355 with yield stress equal to $3.45 \mathrm{t} / \mathrm{cm}^{2}$ and ultimate strength of $4.1 \mathrm{t} / \mathrm{cm}^{2}$.

Table 2: Cross-sections of structural elements for frames C and D.

\begin{tabular}{|l|c|c|}
\hline Beam/Column sections & Frame C & Frame D \\
\hline Beams B1, B2, B3 and B4 & HEA300 & HEA300 \\
\hline Columns C1, C3 and C5 & HEB260 & HEA500 \\
\hline Columns C2, C4 and C6 & HEA260 & HEA500 \\
\hline Total tonnage per frame & 4.053 & 5.86 \\
\hline
\end{tabular}

\section{STRUCTURAL ANALYSIS MODELLING}

To evaluate the structural behaviour of the case study frames, the mathematical model for each frame was analysed using the non-linear version of finite element package SAP2000 [5]. Frames' columns and beams were modelled using the beam-column element available in the programme that allows the development of concentrated plastic hinge at members ends. The precast infill panels were simulated by defining a pair of diagonal crossed tension and compression struts. The compression struts were acquired equivalent dimensions representing the effective stiffness of the panels. For such purpose, the thickness of each compression strut was taken equal to the panel thickness and its width was calculated based 
on the results extracted from a simple finite element model for the panel wall as will be shown later in details. On the other hands, the tension strut was simulated to represent an equivalent area for the resultant of the horizontal and vertical component of the reinforcement mesh used to reinforce the panel. The crossed tension and compression struts area connected through multi-plastic links to the beams. These links are representing the connection of the panels to steel supporting beams. Fig. 2 shows the finite element idealization to analysed frames with blow-up to connections between beam and tension/compression struts through multi-elastic links.

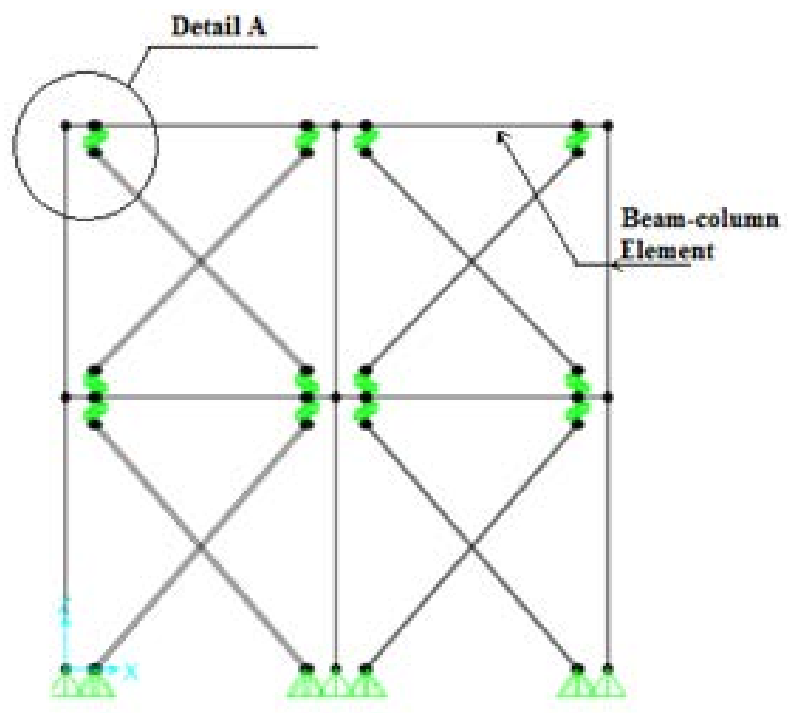

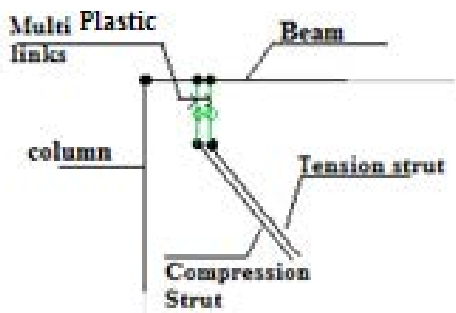

Detail A

Figure 2: Finite element idealization to studied frames.

\subsection{Effective area and stiffness of compression strut}

The thickness of the compression strut can be taken equal to wall thickness, while the equivalent width of compression strut can be computed by modelling the panel using finite element [6]-[8]. For such purpose, the panel was modelled using shell element with support articulation assigned for compression corners only as hinged support in bottom compression corner and roller support in the upper corner, so the resultant of the reaction forces can be replaced with inclined strut subjected to compression forces. Joint load of 1 ton was applied in lateral direction at the location of roller support nodes and the results was obtained as shown in Fig. 3(a) which shows the panel model. For the studied frames with $6 \times 4 \mathrm{~m}$ dimension panels, the effective panel width (L) was calculated $6 \mathrm{~m}$ representing frame width reduced by column width and $400 \mathrm{~mm}$ gap which gives L equal to $5.1 \mathrm{~m}$. The effective panel height $(\mathrm{H})$ was calculated $4 \mathrm{~m}$ representing frame height reduced by half the beam height and half the supporting angle leg which gives $\mathrm{H}$ equal to $3.8 \mathrm{~m}$. The panel thickness was assumed to be $100 \mathrm{~mm}$ reinforced with $5 \Phi 10$ per meter for both longitudinal and transversal direction. The cylinder compressive strength of concrete utilized for the panel was assumed to be 30 $\mathrm{N} / \mathrm{mm}^{2}$. the models consist of two columns an outer 500 and beam with max depth $300 \mathrm{~mm}$. Fig. 3(b) shows the results of the panel analysis. As can be noted, the stresses within the wall were concentrated along the wall diagonal forming a member of the rectangular 
cross-section. The area outside this diagonal had minor stresses which can be ignored. From this the effective width of the compression member that replace the precast wall can be obtained using the following equations:

$$
\begin{gathered}
\delta_{\text {diagonal }}=\delta_{\mathrm{h}} \cos (\theta), \\
\mathrm{K}_{\mathrm{P}}=\left(\mathrm{P}_{\mathrm{h}} / \cos (\theta)\right) /\left(\delta_{\text {diagonal }}\right),
\end{gathered}
$$

where $K_{P}$ is equivalent strut stiffness and the equivalent strut width shall be calculated through the below equation:

$$
\mathrm{KP}=\frac{E A}{L}
$$

where, $\mathrm{E}$ is the elastic modulus of concrete, $\mathrm{A}$ is the cross-section area of the equivalent compression strut and $\mathrm{L}$ is the diagonal inclined strut length.

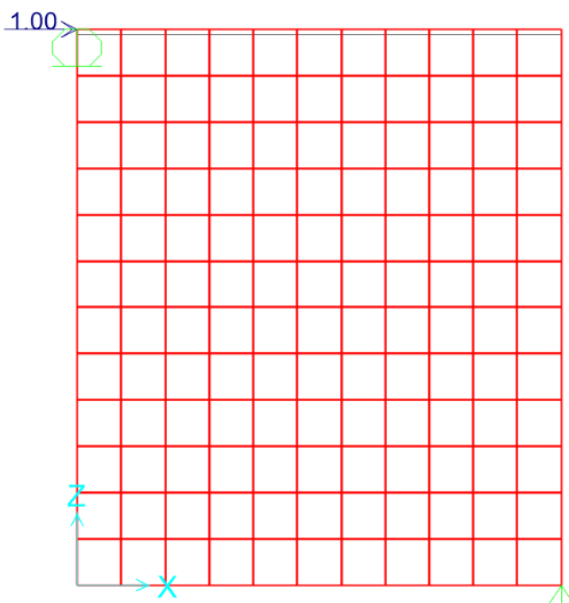

(a)

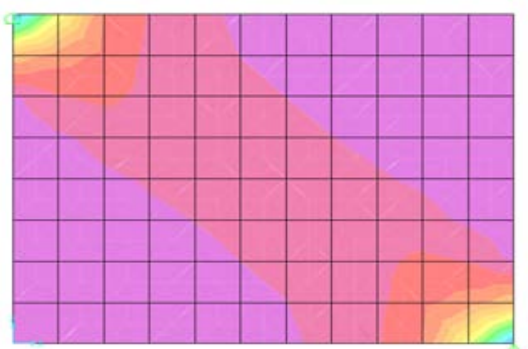

(b)

Figure 3: (a) Idealization of precast panel; and (b) Finite element results.

Determining that $\delta_{\mathrm{h}}$ was estimated as $0.00004077 \mathrm{~m}$, the stiffness $\left(\mathrm{K}_{\mathrm{p}}\right)$ of the compression strut was calculated as $35434.343 \mathrm{t} / \mathrm{m}$ and its effective width as $1.01 \mathrm{~m}$.

\subsection{Tension strut}

Tension strut can be calculated simply by considering area equivalent to the effective area of steel reinforcement which provide tension stiffness of the precast cladding panel wall.

\subsection{Connection between concrete panel and steel frame}

As previously indicated, each panel wall was modelled using two pairs of compression and tension struts extending in both diagonal directions of the panel and connected to the frames' steel beams. To simulate the connection between steel beam and the diagonal struts, Multi-plastic links were assigned. The properties of these links such as nonlinear stiffness, failure load, and displacement criteria were computed utilizing Finite element model. For 
such purpose, the Steel beam was modelled using shell elements considering the nonlinear properties for the steel material. The concrete panel was assumed to be connected to the steel beam through steel angle $(100 \times 100 \times 10)$ attached from one side to the concrete panel by two anchors which are represented as two points on the steel angles through which the panel loads are transferred to the steel beam and from the other side, the steel angle was welded to steel beam as shown in Fig. 4.
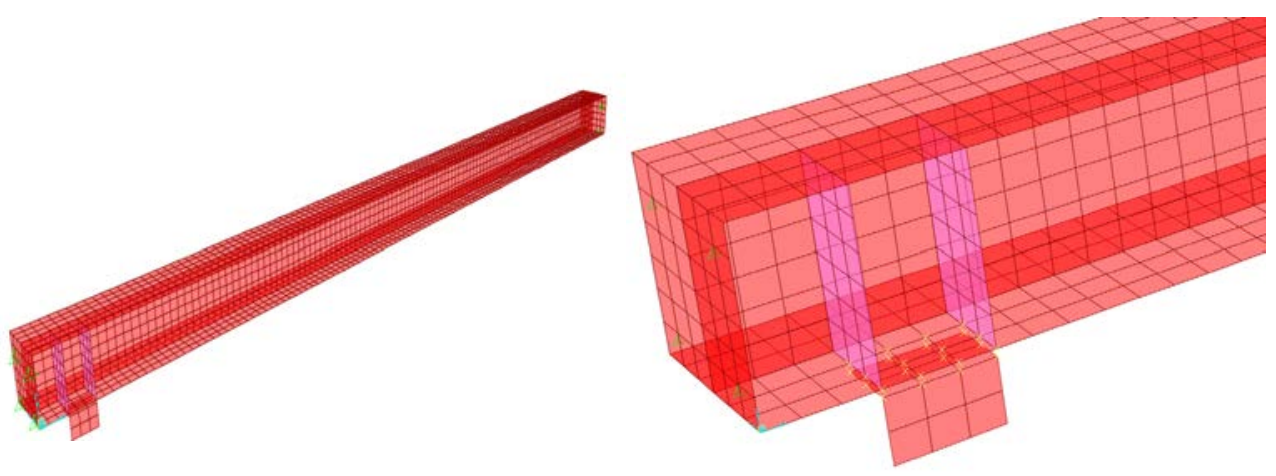

Figure 4: Idealized mode for steel beam and its connection to panel.

The connecting angle is loaded laterally and vertically with incremental increased load applied at the location of the two steel anchors and having an angle equal to the diagonal angle of the panel. Each anchor is loaded with $50 \%$ of the total applied load. To ensure that failure occurs at the anchors' locations, $10 \mathrm{~mm}$ thick vertical stiffeners were provided at the locations of the connections, each on one side of connecting steel angle. Nonlinear analysis was performed to obtain the force-displacement curve for the connection. Stiffness, failure loads and corresponding deformation in both horizontal and vertical directions for the connection based on utilizing bolt diameter $12 \mathrm{~mm}$ assuming the beam profile is HEA 300 are given in Tables 3 and 4 which show the failure loads and associated deformations in case of using bolts diameters $16 \mathrm{~mm}$ and $20 \mathrm{~mm}$, too.

\section{ANALYSIS RESULTS}

\subsection{Analysis for wind loads}

Both frames A and B were loaded with incremental lateral load having a uniform pattern representing wind. Frame A was studied twice, once with the contribution of wall panels and another without panel contribution. Fig. 5 shows the top floor lateral deformation against base shear for analysed frames. As can be noted, frame A with the contribution of the panel was having lateral stiffness exceeding that of frame B which is designed to satisfy the code lateral drift. Consequently, great saving in steel weight can be achieved by considering the contribution of wall panels. 

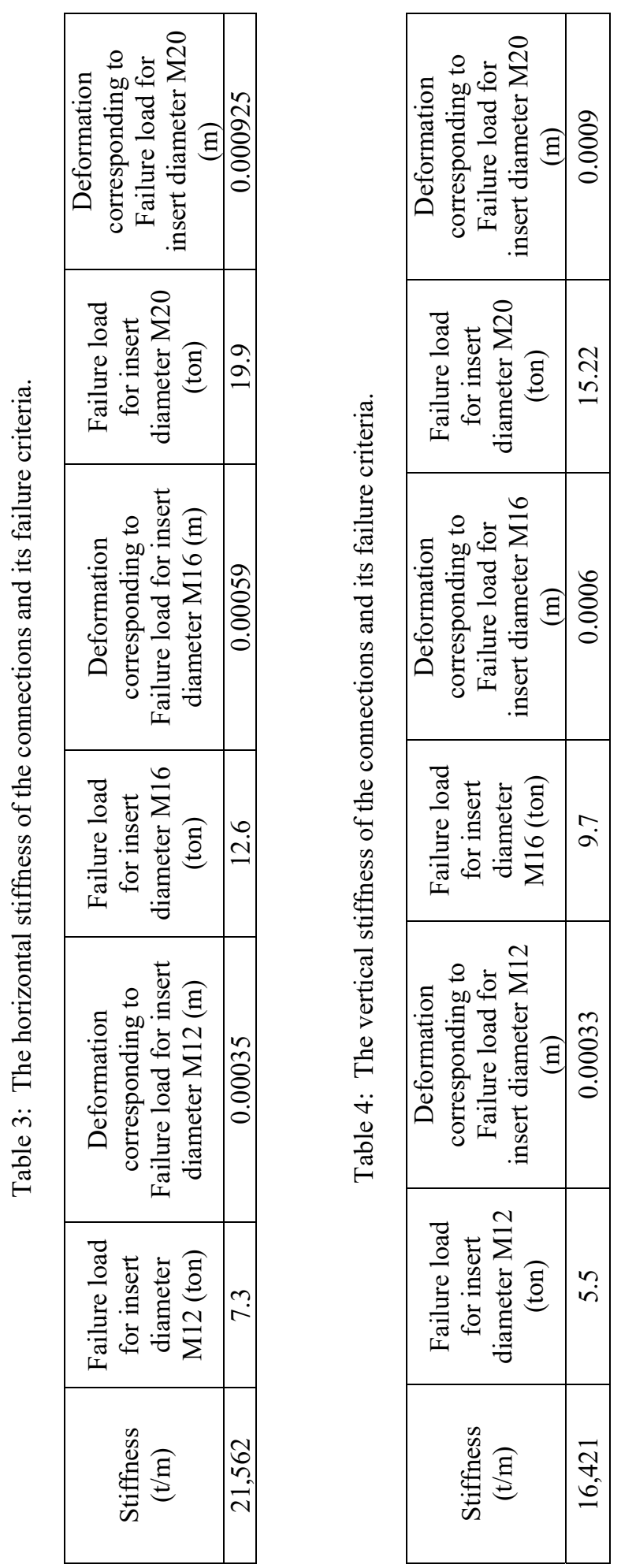


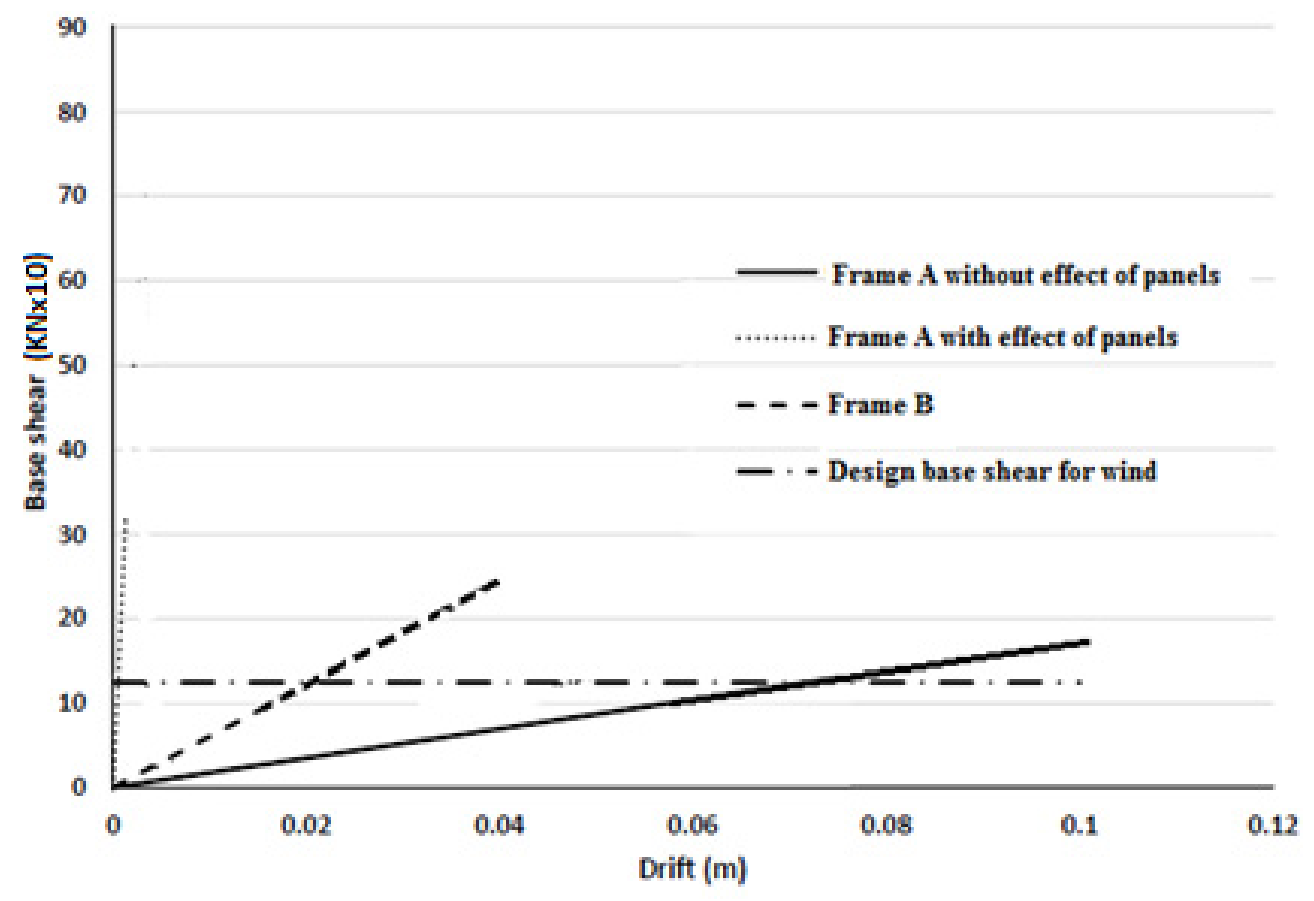

Figure 5: Base shear - top floor deformation under incremental uniform lateral loads.

\subsection{Analysis for seismic loads}

Both frames $\mathrm{C}$ and $\mathrm{D}$ were loaded with incremental lateral load having an inverted triangle loading pattern representing the lateral earthquake load. Frame $\mathrm{C}$ was studied twice, once with the contribution of wall panels and another without wall panel contribution. Fig. 6 shows the top floor lateral deformation against base shear for analysed frames. As can be noted, frame $\mathrm{C}$, which is mainly designed for strength requirements, ignoring drift limits, with the contribution of the panel was having initial lateral stiffness exceeding that of frame $\mathrm{D}$ which was designed to satisfy both code strength and drift requirements. However, once the panels connections to steel frame start to fail, the frame stiffness start degrading and at ultimate stage started to behave as bare frame. In other words, started to behave as if frame $\mathrm{C}$ is bare frame without contribution. This behaviour indicated that:

1. For minor and moderate earthquakes when controlling drift is the key issue, the contribution of the exterior precast concrete panels can improve significantly the behaviour of the frames by controlling their drift. This was clear from comparing the behaviour of Frames $\mathrm{C}$ with and without wall panel contribution.

2. The need for controlling drift in frames result in increasing the strength of the frames significantly due to the increase in steel cross-sections. This can be detected from examining the behaviour of frame $\mathrm{d}$ and frame $\mathrm{C}$.

3. For major earthquake when strength is the key issue, behaviour of frames with exterior precast panels can be significantly improved by utilizing strong connections between the wall panels and the steel frames. 


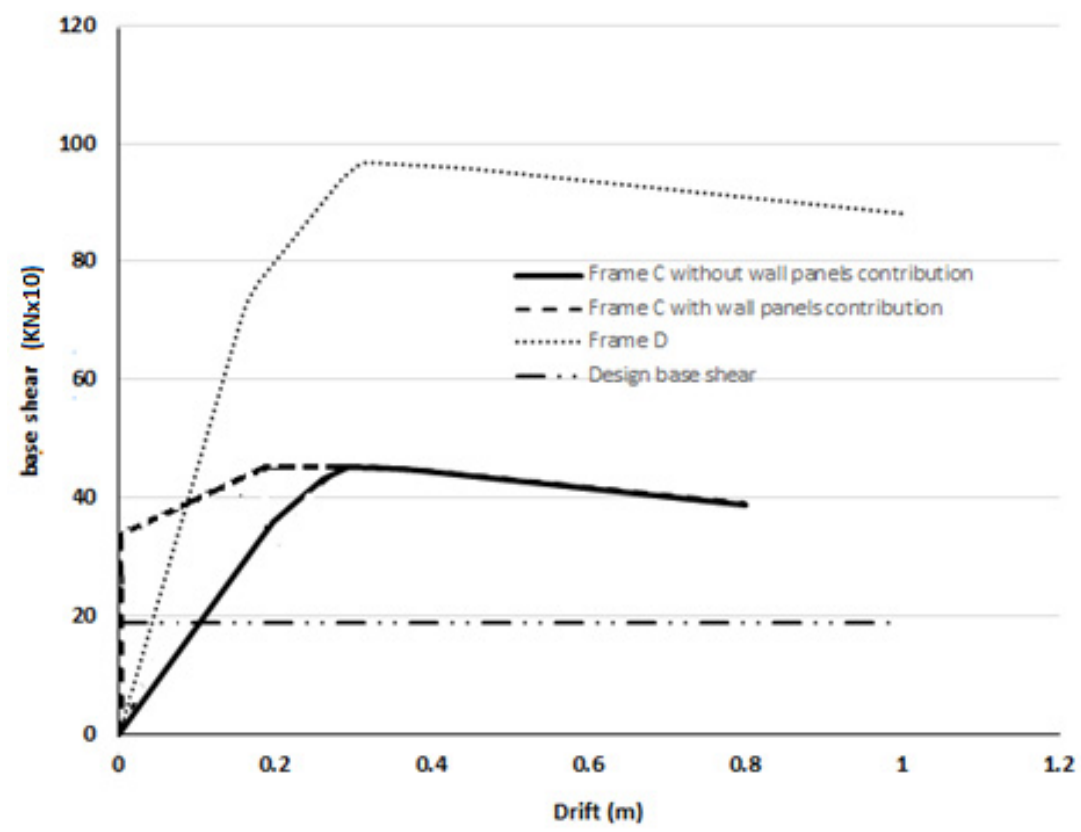

Figure 6: Base shear - top floor deformation under inverted triangular lateral loads.

With regards to plastic hinging pattern, Figs 7 and 8 show the plastic hinges formed in both frames prior to failure. As can be noted, frame $\mathrm{C}$ failed by forming story mechanism at 1 st story, while frame D failed by forming beam-column sway mechanism. Although the failure of frame $\mathrm{D}$ is recommended compared to the failure of frame $\mathrm{C}$, it should be noted that both frames were designed as intermediate moment resisting frames with same $\mathrm{R}$ value equal to 5 according to Egyptian code [4] and with no strong column-weak beam special ductility requirements. The only difference as stated before was that frame $\mathrm{D}$ satisfied drift limits of $2 \%$ as per code requirements.
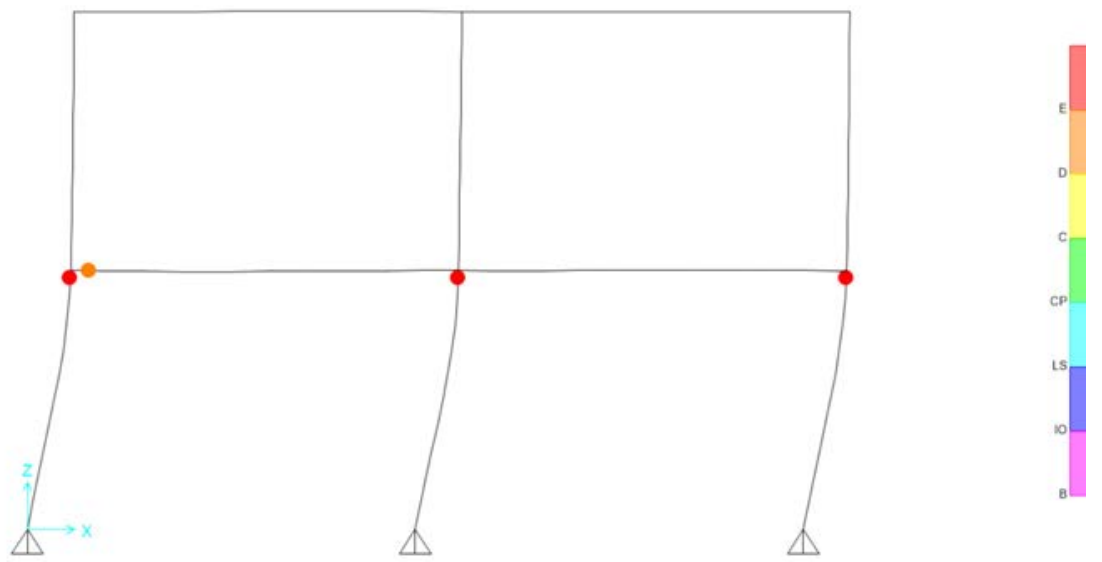

Figure 7: Plastic hinging pattern for Frame $\mathrm{C}$ before failure. 

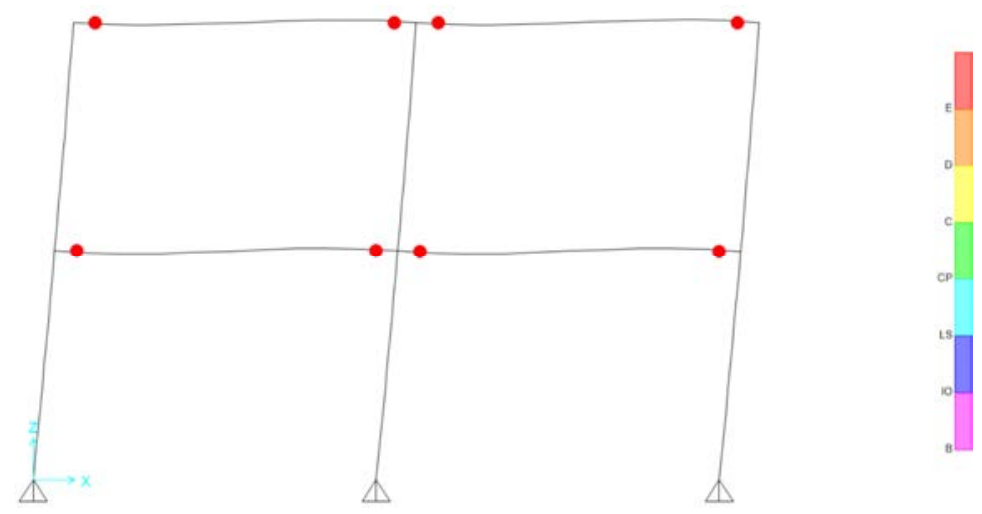

Figure 8: Plastic hinging pattern for Frame D before failure.

\subsection{Parameters affecting the frames behaviour}

To further explore this problem and identify the parameters that affects such frames types, it was decided to examine the behaviour of frames in case of increasing the strength of the wall panel to steel member connection through increasing the bolt diameter. For such purpose the same frame was subjected to monotonically increasing lateral loads having an inverted triangular loading pattern, but with using connections utilizing different bolts diameter $(12 \mathrm{~mm}, 16 \mathrm{~mm}$, and $20 \mathrm{~mm})$ to increase connection strength. The values given in Tables 3 and 4 were used for such purpose. Fig. 9 shows the behaviour of these frames. Obviously, increasing the connection strength increased the frames strength for same lateral drift. In other words, improved the frames seismic behaviour significantly. Consequently, it can be concluded that wall panels improve significantly the frames lateral behaviour and such improvement can be further magnified by using stronger connection between wall panel and the frame.

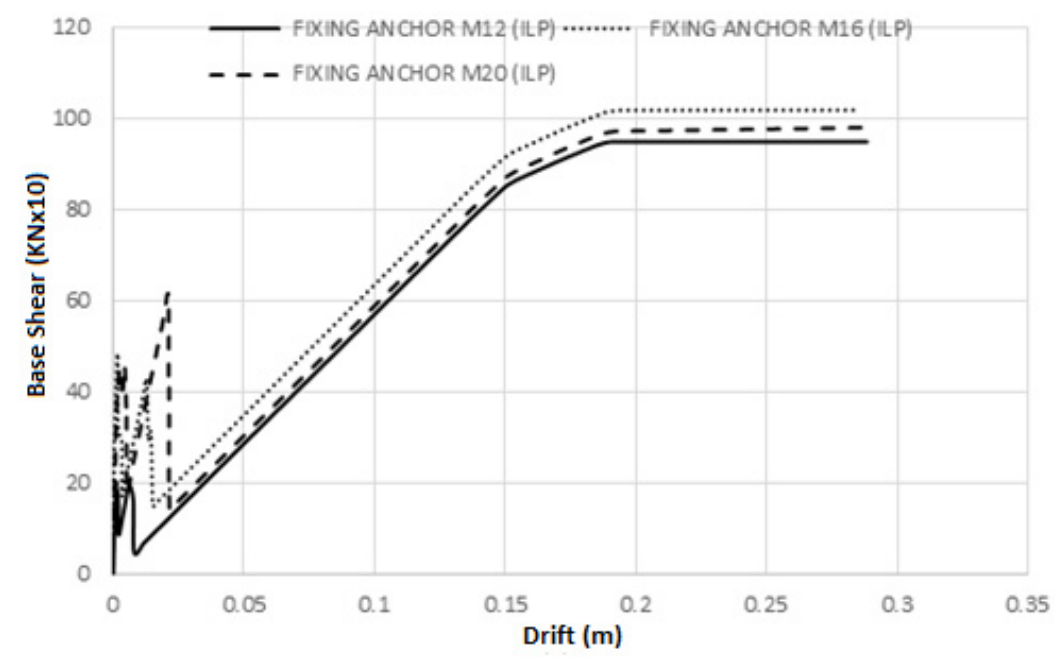

Figure 9: Base shear - top floor lateral displacement for different connection strength. 


\section{CONCLUSION}

Based on provided study, it can be concluded that:

1. The precast concrete external panels can engage efficiently with steel moment resisting frames in resisting lateral loads and controlling their deformation which can lead to reduction in frames weight.

2. For moment resisting frames precast cladding panel can be modelled simply as compression and tension struts and the analysis parameters can be obtained using a simple finite element model with commercial software.

3. For case of wind loads, the contribution of the panels increased frames' initial stiffness, controlling the lateral drift, and limiting the design requirement to satisfying strength requirements only, which will reduce the weight of steel structures significantly.

4. For case of earthquake, the contribution of cladding panels again controlled the lateral drift of the frames, reducing the expected non-structural damage during minor and moderate earthquakes, However, for major earthquake, the connection of panels failed, and the steel frames relayed on resisting lateral earthquake loads by its own ductility. Consequently, it is recommended that the connections between steel frames and panels designed for higher reduction factor than that used for designing the frames and requirements related to strong column-weak beam applied even if the frames area designed as intermediate or ordinary moment resisting frames.

\section{REFERENCES}

[1] Barua, H. \& Mallick, S., Behaviour of mortar infilled steel frames under lateral load. Building and Environment, 12(4), 263-272, 1977.

[2] Gaiotti, R. \& Smith, B., Stiffening of moment-resisting frame by precast concrete cladding. PCI Journal, 37(5), 80-92, 2014.

[3] Goodno, B. \& Craig, J., Modelling of advanced, pre-cast cladding connections for seismic design. Building Research \& Information, 20(5), 313-319, 2007.

[4] Housing Research Building Center, Egyptian code for calculating loads and forces for structural and building works (ECP 201). Code of practice, Egypt, 2012.

[5] Computers and Structures, Inc., SAP2000 v20. Integrated software for structural analysis and design, USA, 2018.

[6] Goodno, B.J., Meyyappa, M., Nagarajaiah, S., Meyyappa, M. \& Nagarajaiah, S.B., A refined model for precast cladding and connections. Ninth World Conference on Earthquake Engineering, pp. 2-9, 1988.

[7] Liauw, T.-C. \& Kwan, K.-H., Nonlinear behaviour of non-integral infilled frames. Computers and Structures, 18(3), 551-560,1984.

[8] Negro, P. \& Lamperti Tornaghi, M., Seismic response of precast structures with vertical cladding panels: The SAFECLADDING experimental campaign. Engineering Structures, 132, 205-228, 2017. 